\title{
EARLY CHILDHOOD SCIENCE EDUCATION: STATE OF THE ART AND PERSPECTIVES
}

\author{
Konstantinos Ravanis \\ University of Patras, Greece
}

The last twenty-five years have seen an increase in the development of an area of educational research and implementation which is known internationally as Early Childhood Science Education. In fact, this is a broad framework within which different theoretical trends coexist with corresponding research orientations and fields of teaching applications. These trends converge in an effort to study the mechanisms of initiation of children aged 4-8 years into the properties of the materials and objects and into the phenomena and concepts of Natural Sciences.

When the first relevant efforts began to take shape, valid questions were raised as to whether the systematic approach to Natural Sciences at such an early age was desirable, possible and feasible.

- The question of whether it was "desirable" was easily answered, since an overview of all the traditional pedagogical trends highlighted the great importance they attached to the appropriation of the natural world (e.g., Froebel, 1909; Montessori, 1914; Dewey, 1943/1990). Although the type of pedagogical practices they proposed was different, their attachment to the discovery of natural objects and phenomena was unvarying.

- Whether it was "possible" was illuminated by research in Genetic, Evolutionary, Developmental and Cognitive Psychology, despite their different starting points and orientations. Strong findings in Psychology research have shown that introducing the natural world to young children is not only possible, but happens regardless of whether we want it to, as they spontaneously begin to build relevant mental representations as early as infancy (Piaget, 1926; Vygotski, 1934/1962).

- Within the framework of Science Education there emerged the first research papers that argued that the effective involvement of young children in the learning of Natural Sciences is feasible as a subject of specialized teaching interventions (Fleer, 1996; Ravanis \& Bagakis, 1998).

In the 1990s, we gradually formulated and proposed a classification of the research and implementation trends for Early Childhood Science Education (Ravanis \& Bagakis, 1998). As it appeared at the time, three distinct approaches affected every relative effort: the empiricist, the Piagetian and the socio-cognitive. Although the three are still present but different in substance than at that time, we will try to illuminate them taking into account their present momentum and perspective. We will also highlight the fourth one, the socio-cultural, which is gradually taking up more and more space.

\section{Contemporary trends: A classification}

The empiricist approach was established during a long course through implicit processes whose initial appearance can be traced back to traditional early childhood pedagogy. As mentioned above, in all historically significant pedagogical theories the need for the initiation of small children into the physical world was clearly formulated, but this tendency was of a more philosophical dimension than a systematic didactic orientation. This tradition seems to have quickly combined with early behavioral attitudes towards learning as well as general empiricist ideas 
regarding the development of intelligence. The unregulated mixing of these influences also created an empirical tradition lacking in clear-cut rules in which a latent hypothesis prevailed: the successful learning and teaching of Natural Sciences is achieved through the creation of environments which foster the "transfer" of scientific information and knowledge to children's thinking. Here the balance between the factors of a teaching process has fixed characteristics. The subject of the teaching is drawn directly from Natural Sciences based on empirical simplifications and subjective considerations as to whether it is possible for it to be taught to younger children. The teacher is at the center of the process: they set the working topics, define the boundaries of the discussions, they propose and present experiments and guide the teaching activities, ask questions and give the "right" answers, thus maintaining a strong leadership role. Within this context, the children follow the teacher's initiatives, participate in pre-defined activity development plans and answer questions (Brown, 1989; Conezio \& French, 2002; Miller, 2016).

The second framework was created by pedagogues who adopted the basic theoretical elements of Piagetian Genetic Epistemology. It is well known that this theory was based on the assumption that the development of intelligence is not the result of the recording in the mind of perceptual data from the environment, but the construction of logical structures within the context of a continuous interaction of the active subject with the world in which it develops. Thus, in order to introduce the natural world in early childhood, Kamii (1982) and Kamii \& De Vries (1978) suggested a turn to physical-knowledge activities which focus on children's activity with the pedagogical material and generally the objects at its disposal with which to interact. This choice is entirely distinguishable from the teaching of science, which focuses on theories, models, laws and experimental methodology. During physical-knowledge activities, choices and action patterns, individual and team work, the children's ordinary difficulties and insurmountable obstacles are the subject of study at the research level and the subject of a teaching intervention at the level of pedagogical practices (Crahay \& Delhaxe, 1988). Here the organization of the environment is such as to maximize the ability of children to work, transform and develop patterns related to the substances and the objects. The role of teachers during the activities is to support, encourage and facilitate the pupils as well as to record the creative choices and the impasses of the children's actions (Ravanis, 1994). This recording allows estimating and predicting the reorganization of space and the choice of materials with an aim to achieve increasingly effective interactions.

The question of didactic interaction processes has emerged as a basic dimension in modern Science Education. Indeed, the attempt to move from children's day-to-day thinking to thought-patterns compatible with scientific knowledge also led Early Childhood Science Education on a course of forming the socio-cognitive current, i.e., a third distinct framework, dominated by both the recording of the mental representations of children aged 4-8 (e.g., Kampeza, 2006; Prokop, Usak \& Erdogan, 2011), and the study of teaching situations in which representations can be transformed (e.g., Ergazaki \& Zogza, 2013; Ntalakoura \& Ravanis, 2014). In this instance, a strong influence was exerted by post-Piagetian theories on learning as well as a limited focus on Vygotski's analysis of the development of scientific concepts (Perret-Clermont, 1980; Weil-Barais, 1994). These theoretical tools have highlighted on the one hand the importance of the need for the specific handling of the constraints of young children's thinking and, on the other hand, the ability to achieve remarkable cognitive progress when they process the concepts and phenomena of Natural Sciences. As part of this socio-cognitive approach, the teacher or researcher intervenes to create conditions for exploration and discovery in which the pupil is more likely to construct new knowledge by transcending the various types of obstacles. Children work in these conditions; they participate in organized instances of symmetrical or asymmetric communication; they argue; they put forth predictions and assumptions which they explore; and exploit multiple representation systems in order to reconstruct their reasoning.

In recent years, the concept of the precursor model seems to successfully give shape to the issues that arise regarding the socio-cognitive approach. Precursor models are cognitive entities which: a) interpose themselves between the original children's representations and the scientific models used in education, and b) allow pupils to put forth thought processes which, on the one hand, surmount the obstacles of their thinking and, on the other, are compatible with scientific ones (Weil-Barais, 2001). The structure and content of the precursor model is put together by a systematic matching of young children's difficulties and the relevant characteristics of the scientific reference model. Thus, didactic intervention is an attempt to create the conditions for children's active involvement with an aim to reconstruct their thinking at the precursor model level (Ravanis, Koliopoulos \& Boilevin, 2008; Ravanis, Christidou \& Hatzinikita, 2013). This perspective seems to offer a field of systematic work for the initiation of younger children into Natural Sciences, as it allows for a balance between what is desired and what is possible. It also contributes to a convergence between Early Childhood Education and Science Education and in some way establishes a common field of research and implementation. 
Whereas, in socio-cognitive strategies the center of gravity lies in the systematic utilization of the social environment in learning, socio-cultural and cultural-historical approaches are based on the major Vygotskian hypothesis according to which learning and development stem from the cultural, historical and social elements of the environment (Hedegaard \& Fleer, 2008). Thus, a socio-cultural framework requires a shift from the orientation in which the emphasis on knowledge is the main subject of teaching activities, in a direction where emphasis is given to the processes through which the context bestows meaning on every cognitive acquisition. This requires a holistic approach to children's scientific thinking which has implications at the methodological level, in terms both of the organization of teaching activities and of their analysis. "This trend is focused on a systemic study of the procedures through which young children develop scientific thinking and the situational characteristics that act as a driving force of this development. In that framework, qualitative and flexible methodologies are replacing quantitative linear approaches of concrete functions, static elements and isolated incidents and circumstances. Integrating everyday reality and real life phenomena, research leads to a better contextual understanding and to a deeper conceptualization of the process of the individual's development as well as of the educator's mediating role as a cultural tool" (Fragkiadaki \& Ravanis, 2016, p. 312).

Therefore, within the socio-cultural framework we aim: a) at the level of research, to understand how children approach Natural Science concepts and phenomena in a dialectic relationship with cultural, social and physical elements of the environment; and b) at the level of didactic procedures, to create conditions for the coordination between a personal intellectual progress and the situational characteristics that appear in a collective scientific experience in school. In such a perspective, the teacher organizes and supports a communication framework and a school environment which allows the emergence and exploitation of elements from overall human activity. The pedagogical material and the structure of the teaching activities allow the simultaneous emergence of the intellectual (cognitive, imaginary, etc.), affective, bodily, and social parameters of the situations unfolding in the classroom. Children develop initiatives, they are continuously interacting and communicating with their classmates and teachers, using the materials in many ways, playing symbolic games in which they take on roles and thus approaching the physical world from different paths (Hadzigeorgiou, 2001; Fleer \& Robbins, 2003; Fragkiadaki \& Ravanis, 2014; Fleer, 2015; Herakleioti \& Pantidos, 2016).

\section{Discussion and Perspectives}

The classification of the different trends we have presented underscores the establishment of a distinct area of research and application which creates a break in the long tradition of Early Childhood Education and the relatively shorter one of Science Education.

The empiricist approach prevailed until the 1990s but then lost its momentum because, on the one hand, it was not linked to research and did not lead to an explicit formulation, while on the other hand it gradually began to appear weak compared to other strategies. However, even today, when educational practices evolve away from academic environments, whether it involves the management of classroom routines or the development of curricula and educational material of all kinds, the empiricist perspective is still influential.

The Piagetian theoretical framework offers significant opportunities for the development of Natural Science activities in early childhood education. It is recognized as a distinct trend but has not gained much scope as it appears that some factors have created constraints. First of all, given that these teaching strategies always involve the handling of objects by children, these objects must be amenable to being transformed into teaching materials and must also be safe in the hands of children. Moreover, the increased demands in terms of time and infrastructure on the part of the knowledge discovery processes are usually incompatible with formal curricula. In addition, the theoretical reference framework of this approach is not conducive to the development and study of didactic-social interactions that have gradually begun to become of particular interest in Science Education.

That is precisely why the socio-cognitive approaches based on the dynamics of the research that identified the mental representations of young children were developed and created a tradition dominated by the expectation of cognitive transformation. However, this route risks deviating from established practices in search of knowledge with young children, i.e., pedagogical activity that passes through areas of mental formation such as play and imagination. In this respect, there is always room for criticism but also for adapting and improving socio-cognitive teaching choices.

The socio-cultural framework for the approach to Natural Sciences in kindergarten and primary school classes leads to the creation of new learning environments which allow the conceptualization of the higher mental func- 
ISSN 1648-3898/Print/

ISSN 2538-7138/Online/

tions as social relations and the development of scientific thinking as a transition from the interpsychological to the intrapsychological level. This modern trend, which is to some degree complementary to Piagetian and sociocognitive perspectives, has yielded interesting research results and has already established a particular direction within Early Childhood Science Education.

These four approaches, although distinct at the level of theory and research, overlap in pedagogical applications. This is to be expected as the needs of the actual classrooms, the choices of teachers and the general guidelines of the programs impose real teaching situations which bring together and utilize elements of different origins. Yet far from creating a problem, this is a strong indication of the dynamic nature and effectiveness of today's Early Childhood Science Education.

\section{References}

Brown, S. E. (1981). Bubbles, rainbows and worms. Science experiments for preschool children. Mt. Rainier, MD: Gryphon House. Conezio, K., \& French, L. (2002). Science in the preschool classroom: capitalizing on children's fascination with the everyday world to foster language and literacy development. Young Children, 57 (5), 12-19.

Crahay, M., \& Delhaxhe, A. (1988). Agir avec les rouleaux. Agir avec l'eau. Bruxelles: Labor.

Dewey, J. (1943/1990). The school and society. The child and the curriculum. Chicago: University of Chicago Press.

Ergazaki, M., \& Zogza, V. (2013). How does the model of Inquiry-Based Science Education work in the kindergarten: The case of biology. Review of Science, Mathematics and ICT Education, 7 (2), 73-97.

Fleer, M. (1996). Early learning about light: mapping preschool children's thinking about light before, during and after involvement in a two week teaching program. International Journal of Science Education, 18 (7), 819-836.

Fleer, M., \& Robbins, J. (2003). "Hit and Run Research" with "Hit and Miss Results" in Early Childhood Science Education. Research in Science Education, 33, 405- 431.

Fleer, M. (2015). A cultural-historical model of early childhood science education. In M. Fleer \& N. Pramling (eds.), A culturalhistorical study of children learning science (pp. 199-213). Dordrecht: Springer.

Fragkiadaki, G., \& Ravanis, K. (2014). Mapping the interactions between young children while approaching the natural phenomenon of clouds creation. Educational Journal of the University of Patras UNESCO Chair, 1 (2), 112-122.

Fragkiadaki, G., \& Ravanis, K. (2016). Genetic research methodology meets Early Childhood Science Education Research: A cultural-historical study of child's scientific thinking development. Cultural-Historical Psychology, 12 (3), 310-330.

Froebel, F. (1909). Friedrich Froebel's pedagogics of the kindergarten. New York: D. Appleton and Company.

Hadzigeorgiou, Y. (2001). The role of wonder and "romance" in early childhood science education. International Journal of Early Years Education, 9, 63-69.

Hedegaard, M., \& Fleer, M. (2008). Studying children. A cultural historical approach. Glasgow: Open University Press.

Herakleioti, E., \& Pantidos, P. (2016). The contribution of the human body in young children's explanations about shadow formation. Research in Science Education, 46 (1), 21-42.

Kamii, C. (1982). La connaissance physique et le nombre à l'école enfantine. Approche piagetiénne. Pratiques et Théorie, cahier n. 21. Genève: Université de Genève.

Kamii, C., \& De Vries, R. (1978). Physical Knowledge in preschool education: Implications of Piaget's theory. Englewood Cliffs, NJ: Prentice-Hall).

Kampeza, M. (2006). Preschool children's ideas about the Earth as a cosmic body and the day/night cycle. Journal of Science Education, 5 (1), 119-122.

Miller, J. (2016). The Physics of sound. Using a learning center to promote STEM development in early childhood. Science and Children, 54 (4), 34-40.

Montessori, M. (1914). Dr Montessori's own Handbook. New York: Frederick Stokes and Company.

Ntalakoura, V., \& Ravanis, K. (2014). Changing preschool children's representations of light: A scratch based teaching approach. Journal of Baltic Science Education, 13 (2), 191-200.

Perret-Clermont, A. N. (1980). Social interaction and cognitive development in children. London: Academic Press.

Piaget, J. (1926). La représentation du monde chez l'enfant. Paris: Alcan.

Prokop, P., Usak, M., \& Erdogan, M. (2011). Good predators in bad stories: Crosscultural comparison of children's attitudes towards wolves. Journal of Baltic Science Education, 10 (4), 229-242.

Ravanis, K. (1994). The discovery of elementary magnetic properties in pre-school age. A qualitative and quantitative research within a Piagetian framework. European Early Childhood Education Research Journal, 2 (2), 79-91.

Ravanis, K., \& Bagakis, G. (1998). Science education in kindergarten: Sociocognitive perspective. International Journal of Early Years Education, 6 (3), 315-327.

Ravanis, K., Koliopoulos, D., \& Boilevin, J.-M. (2008). Construction of a precursor model for the concept of rolling friction in the thought of preschool age children: a socio-cognitive teaching intervention. Research in Science Education, 38 (4), 421-434.

Ravanis, K., Christidou, V., \& Hatzinikita, V. (2013). Enhancing conceptual change in preschool children's representations of light: a socio-cognitive approach. Research in Science Education, 43 (6), 2257-2276.

Vygotski, L. S. (1934/1962). Thought and langage. Cambridge Ma: MIT Press. 
Weil-Barais, A. (1994). Heuristic value of the notion of zone of proximal development in the study of child and adolescent construction of concepts in physics. European Journal of Psychology of Education, 9 (4), 367-383.

Weil-Barais, A. (2001). Constructivist approaches and the teaching of science. Prospects, 31 (2), 187-196. 